\title{
Separating microbial respiration of exudates from root respiration in non-sterile soils: a comparison of four methods
}

\author{
Y. Kuzyakov* \\ Institute of Soil Science and Land Evaluation (310), University Of Hohenheim, Emil-Wolff-Strasse 27, D-70593 Stuttgart, Germany
}

Received 7 February 2002; received in revised form 10 June 2002; accepted 14 June 2002

\begin{abstract}
Partitioning the root-derived $\mathrm{CO}_{2}$ efflux from the soil into actual root respiration (RR) and microbial respiration of exudates and root residues is very important for determining the carbon (C) and energy balance of soils. Studies based on artificial root environments like hydroponics or sterile soils give unrealistic figures for $\mathrm{C}$ partitioning and are unsuitable for predicting $\mathrm{C}$ flows under natural conditions. To date, only four methods have been suggested to separate RR and rhizomicrobial respiration in non-sterile soils: (1) the isotope dilution method, (2) the model rhizodeposition technique, (3) modeling of ${ }^{14} \mathrm{CO}_{2}$ efflux dynamics, and (4) the exudate elution procedure. All four methods are based on the pulse labeling of shoots in a ${ }^{14} \mathrm{CO}_{2}$ atmosphere and subsequent monitoring of ${ }^{14} \mathrm{CO}_{2}$ efflux from the soil. However, the basic assumptions and principles of these methods, as well as the results observed in the original papers, all differ from one another. This study describes the separation of RR of Lolium perenne grown on a loamy Haplic Luvisol from microbial respiration of rhizodeposits by means of all four methods under the same experimental conditions.

In spite of alternative principles, the isotope dilution and the ${ }^{14} \mathrm{CO}_{2}$ dynamics methods show a similar level of RR: accordingly, 39 and $45 \%$ of total root-derived $\mathrm{CO}_{2}$ efflux were accounted for by $\mathrm{RR}$. The remainder is rhizomicrobial respiration. The exudate elution method, which underestimates the total rhizodeposition, shows that at least $19 \%$ of root-derived $\mathrm{CO}_{2}$ is produced by exudate decomposition. The microbial respiration of rhizodeposits calculated using the model rhizodeposition technique is also underestimated. The exudate elution method is the only procedure allowing physical separation of both $\mathrm{C}$ flows. The assumptions and principles of all four methods are reviewed and the effects of possible shortcomings on the separation results are discussed. In conclusion, RR contributes about 40-50\% to the rootderived $\mathrm{CO}_{2}$ efflux. The remaining 50-60\% comprise the microbial decomposition of root exudates and other rhizodeposits. The longer the period of monitoring the $\mathrm{CO}_{2}$ efflux after the pulse labeling is, the higher the contribution of rhizomicrobial respiration to the total rootderived $\mathrm{CO}_{2}$ efflux from soil. (C) 2002 Elsevier Science Ltd. All rights reserved.
\end{abstract}

Keywords: Separation methods; Root respiration; Rhizosphere respiration; Rhizodeposition; Root exudates; ${ }^{14} \mathrm{C}$ pulse labeling; Lolium perenne; C turnover

\section{Introduction}

Differentiating the root-derived $\mathrm{CO}_{2}$ efflux from the soil into actual root respiration (RR) on the one hand and into microbial respiration of exudates and of root residues on the other hand is very important in quantifying the $\mathrm{C}$ and energy balance of the soil. Exudates and root residues are energyrich; they enhance the underground $\mathrm{C}$ stock and are metabolized by soil microflora. These $\mathrm{C}$ sources, which are readily available to microorganisms, contribute to fast $\mathrm{C}$ turnover in the soil and to higher microbial activity in the rhizosphere when compared with root-free soil. Stimulation of microbial growth and activity around roots increases the mineralization of native soil organic matter (reviewed by

* Tel.: +49-711-459-2327; fax: +49-711-4593-117.
Cheng and Kuzyakov (2002) and Kuzyakov (2002)) and subsequently increases the availability of mineral nutrients. In contrast to the root exudates, $\mathrm{CO}_{2}$ originating from $\mathrm{RR}$ cannot be used by microorganisms for their growth: it is energy-poor and does not affect the turnover of microbial biomass and soil organic matter. Therefore, accurate $\mathrm{C}$ and energy budgets of the soil cannot be determined without separately estimating RR and microbial utilization of root exudates. As stated by Killham and Yeomans (2001), "Discriminating between $\mathrm{CO}_{2}$ which is directly derived from $\mathrm{RR}$ and that which is derived from mineralization of the components of $\mathrm{C}$ flow is exceptionally difficult and has presented one of the greatest challenges to quantifying rhizosphere C flow".

The term 'root-derived $\mathrm{CO}_{2}$ ' is used here to describe the sum of $\mathrm{RR}$ and $\mathrm{CO}_{2}$ evolved by microbial decomposition of 
exudates, secretions as well as root residues such as sloughed root cells, root hairs and dead roots. Strictly speaking, the term 'rhizosphere $\mathrm{CO}_{2}$ ', frequently used in the literature, refers to the location of $\mathrm{CO}_{2}$ production; from this point of view it must include not only $\mathrm{RR}$ and $\mathrm{CO}_{2}$ evolved by microbial utilization of exudates, but also the $\mathrm{CO}_{2}$ derived by microbial decomposition of rhizosphere soil organic matter.

Nutrient solution cultures (Helal and Sauerbeck, 1991; Meharg and Killham, 1991; Hodge et al., 1996; Groleau-Renaud et al., 1998), soil sterilization (Barber and Martin, 1976; Martin, 1977; Merbach et al., 1990; Merbach and Ruppel, 1992) and fumigation techniques (Helal and Sauerbeck, 1991) related to ${ }^{14} \mathrm{C}$ or ${ }^{13} \mathrm{C}$ labeling have been used to investigate microbial respiration of root exudates. The results show that investigations based on environments that are artificial for the roots, like hydroponics or sterile soils, give unrealistic figures for $\mathrm{C}$ partitioning (Bowen, 1980; Schönwitz and Ziegler, 1988; Merbach et al., 1990; Meharg and Killham, 1991; Schulze et al., 1994). This makes them unsuitable for predicting $\mathrm{C}$ flows under natural conditions. Some earlier field studies used the component integration method; this involves manually separating the constituent soil components that contribute to $\mathrm{CO}_{2}$ efflux (i.e. roots, sieved soil, litter), followed by measurements of the specific respiration activity of each component part (Edwards and Harris, 1977; Blagodatsky et al., 1993; reviewed by Hanson et al. (2000)). This method, however, was never broadly applied, probably because of the strong impact of physical separation on the components and the significant change of rhizosphere conditions along with the imperfect separation procedure (reviewed by Hanson et al. (2000)).

More recently, efforts have been made to divide rootderived $\mathrm{CO}_{2}$ (as a sum of $\mathrm{RR}$ and microbial respiration of root-derived organic $\mathrm{C}$ ) into $\mathrm{CO}_{2}$ originating from $\mathrm{RR}$ and that from microbial respiration of root-borne substances during plant growth on non-sterile soils. Four methods have been suggested: The first method, known as isotope dilution, is based on the addition of a solution of unlabeled glucose to the soil and simultaneous ${ }^{14} \mathrm{C}$ pulse labeling of growing plants (Cheng et al., 1993). Using this method, RR of 3 -week-old wheat plants was found to account for about $41 \%$ of the root-derived $\mathrm{CO}_{2}$. The second method, based on adding ${ }^{14} \mathrm{C}$-labeled model rhizodeposits to the soil (Swinnen, 1994), shows that the contribution of RR of 30days-old wheat and barley to the total root-derived $\mathrm{CO}_{2}$ was between 89 and $95 \%$. The third method, based on the dynamics of ${ }^{14} \mathrm{CO}_{2}$ efflux from the soil after ${ }^{14} \mathrm{C}$ pulse labeling of shoots (Kuzyakov et al., 1999, 2001; Kuzyakov and Domanski, 2002), showed that RR and respiration of rhizosphere microorganisms in growing Lolium perenne amounts to 41 and $59 \%$ of root-derived $\mathrm{CO}_{2}$ efflux from the soil, respectively. The contribution of RR varied from 17 to $61 \%$ of total $\mathrm{CO}_{2}$ efflux from the soil, depending on the age of the Lolium plants. A detailed description of these three methods, along with their shortcomings and advantages, is discussed in Kuzyakov (2001) and Kuzyakov and Domanski (2002). The fourth method is based on the elution of ${ }^{14} \mathrm{C}$ labeled exudates from soil before microorganisms utilize them (Kuzyakov and Siniakina, 2001). Here, the $\mathrm{CO}_{2}$ efflux from soil is monitored simultaneously to exudates elution, and water movement is driven by air circulation according to the siphon principle. The siphon elution method shows that at least $19 \%$ of root-derived $\mathrm{CO}_{2}$ can be attributed to soluble organic substances exuded by roots.

In summary, the four methods that have been suggested to separate RR and microbial respiration of rhizodeposits in non-sterile soil show different results. Each is based on many assumptions and has certain shortcomings. It remains unclear whether the different results are method-inherent or reflects environmental and experimental conditions, i.e. different plants, soils, equipment, and environmental conditions, etc. As Hanson et al. (2000) conclude, comparative studies of different methods are sorely needed but unfortunately very rare.

The present contribution describes the separation of RR from microbial respiration of rhizodeposits by means of all four methods described earlier under the same experimental conditions. It is designed to compare methods, independently estimate both $\mathrm{CO}_{2}$ sources, as well as select an appropriate procedure for future studies. A few improvements that help extend the original methods were used in this work.

\section{Material and methods}

\subsection{Soil and test crops}

Soil, a loamy Haplic Luvisol, was taken from the top $10 \mathrm{~cm}$ (Ap horizon) of the University of Hohenheim's longterm field experimental station Karlshof. The soil contains no $\mathrm{CaCO}_{3}$ and has the following characteristics: $\mathrm{pH} 6.0, \mathrm{C}_{\mathrm{t}}$ $1.2 \%, \mathrm{~N}_{\mathrm{t}} 0.13 \%$, sand $4.4 \%$, clay $23 \%$, silt $73 \%$. Each container was filled with $400 \mathrm{~g}$ soil, which was air-dried and sieved on a $2 \mathrm{~mm}$ screen prior to the experiment. A polycarbonate filtration device 'CombiSart' with a volume of $250 \mathrm{ml}$ (Merck ${ }^{\circledR}$-Laborkatalog, 2000 was used as a soil container (Fig. 1, (2)). The overall volume of the device, including the space under the lid, was about $340 \mathrm{ml}$. The lid of the CombiSart device contained three inlets. PVC tubes brought air through the three inlets into the CombiSart device from the output of a membrane pump. The soil was separated from the outlet in the bottom of the CombiSart device by a perforated filter support, delivered together with the filtration device, overlaid by two layers of perforated (holes $=0.5 \mathrm{~mm}$ ) polyethylene. The outlet was connected through a PVC tube to a test tube containing $20 \mathrm{ml}$ of $0.25 \mathrm{M} \mathrm{NaOH}$ for $\mathrm{CO}_{2}$ trapping (Fig. 1, (4)).

One pre-germinated seed of $L$. perenne $\mathrm{L}$. was put into each container and grown under $27 / 22^{\circ} \mathrm{C}$ day/night temperature, $14 \mathrm{~h}$ photoperiod and $400 \mu \mathrm{mol} \mathrm{m}{ }^{-2} \mathrm{~s}^{-1}$ light 


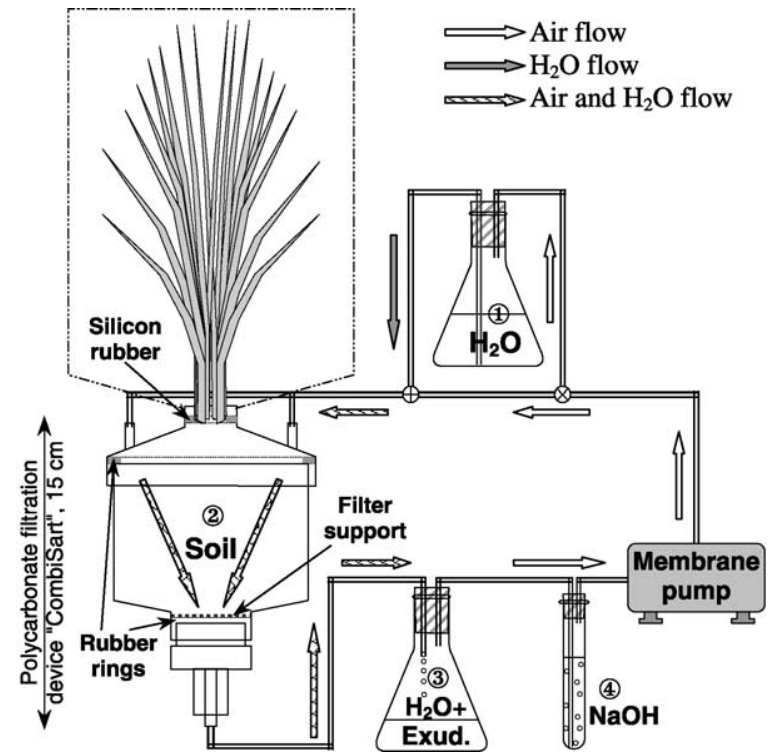

Fig. 1. Experimental setup for separate measurement of RR and exudation. (1)-flask with water for elution, (2)-polycarbonate filtration device CombiSart (Merck ${ }^{\circledR}$-Laborkatalog, 2000) with soil and roots, (3)-collection flask with eluted exudates, (4)- test tube with $\mathrm{NaOH}$ solution for $\mathrm{CO}_{2}$ trapping. $\otimes$-regulation clamp, $\oplus$-joint where air and water flows are connected. For all variants except variant 11, the outlet of the membrane pump was connected directly to the inlets of the CombiSart in the lid and its outlet was connected to the test tube with $\mathrm{NaOH}$ solution for $\mathrm{CO}_{2}$ trapping. (Kuzyakov and Siniakina, 2001).

intensity. The soil water content of each chamber was adjusted daily with deionized water to $60 \%$ of the available field capacity.

The preparation of soil samples, the main soil characteristics, and the growing conditions are the same as described in detail by Domanski et al. (2001).

\subsection{Methods tested}

All four methods known from the literature were compared in one experiment. The experimental design of the experiment is presented schematically in Table 1. Furthermore, in the soil of variants 8 and 10, more glucose was added than recommended in the original contribution of Cheng et al. (1993) and Swinnen (1994). This allowed conclusions to be drawn about applying the method under a wider range of conditions than described in the original papers. Additionally to the pots with planted soil without any glucose addition, the unplanted soil treated with different amounts of ${ }^{14} \mathrm{C}$ labeled glucose was used as controls.

\subsubsection{Isotope dilution method}

The isotope dilution method is described in detail by Cheng et al. (1993). Briefly, unlabeled glucose was added to the soil with plants that were pulse labeled in a ${ }^{14} \mathrm{CO}_{2}$ atmosphere in order to dilute the labeled ${ }^{14} \mathrm{C}$ rhizodeposits. The underlying assumption is that the dilution of ${ }^{14} \mathrm{C}$ by ${ }^{12} \mathrm{C}$ in the $\mathrm{CO}_{2}$ originating from microbial respiration of rhizodeposits is proportional to the amount of unlabeled glucose added. However, only the microbial respiration of exudates is diluted, but the contribution of $\mathrm{RR}$ remains constant. Originally (Cheng et al., 1993), two glucose concentrations were used: 171 and $881{\mu \mathrm{g} \mathrm{Cg}^{-1}}$ soil. Besides the recommended glucose amounts (160 and $800 \mu \mathrm{g} \mathrm{C} \mathrm{g}^{-1}$ soil), one lower $\left(32 \mu \mathrm{g} \mathrm{C} \mathrm{g}^{-1}\right)$ and one higher (4000 $\mu \mathrm{g} \mathrm{C} \mathrm{g}^{-1}$ ) value were also used in our study. Two latter variants (32 and $4000 \mu \mathrm{g} \mathrm{C} \mathrm{g}^{-1}$ ) were tested to check a potential extended use of the method. All four glucose amounts were injected as $20 \mathrm{ml}$ aqueous solution by syringe with a long needle into the soil of variants $5-8$. The injection was concomitant with the ${ }^{14} \mathrm{C}$ pulse labeling of variants $4-8$ and 11 in ${ }^{14} \mathrm{CO}_{2}$ atmospheres.

\subsubsection{Model rhizodeposition method}

This study introduced some improvements of the original model rhizodeposition method described by Swinnen (1994). The original method involved two variants: (1) plants were ${ }^{14} \mathrm{C}$ pulse labeled and no model rhizodeposits

Table 1

Variants and soil treatments used to separate root and rhizomicrobial respiration by means of four methods

\begin{tabular}{|c|c|c|c|c|c|c|}
\hline Variant & Method name & Plant & $\begin{array}{l}{ }^{14} \mathrm{CO}_{2} \text { pulse } \\
\left(\mathrm{kBq} \mathrm{Pot}^{-1}\right)\end{array}$ & $\begin{array}{l}{ }^{12} \mathrm{C}_{\text {glucose }} \\
\left(\mu \mathrm{g} \mathrm{C} \mathrm{g}^{-1}\right)\end{array}$ & $\begin{array}{l}{ }^{14} \mathrm{C} \text { glucose } \\
\left(\mathrm{kBq} \mathrm{Pot}^{-1}\right)\end{array}$ & Author/reference \\
\hline 1 & Control 0 & - & 0 & 0 & 0 & \\
\hline 2 & Control 1 & - & 0 & 32 & 119 & \\
\hline 3 & Control 2 & - & 0 & 160 & 119 & \\
\hline 4 & ${ }^{14} \mathrm{CO}_{2}$ dynamics & + & 118 & 0 & 0 & Kuzyakov et al. $(1999,2001)$ \\
\hline 5 & Isotope dilution & + & 118 & 32 & 0 & Cheng et al. (1993) \\
\hline 6 & Isotope dilution & + & 118 & 160 & 0 & Cheng et al. (1993) \\
\hline 7 & Isotope dilution & + & 118 & 800 & 0 & Cheng et al. (1993) \\
\hline 8 & Isotope dilution & + & 118 & 4000 & 0 & Changed: Cheng et al. (1993) \\
\hline 9 & Model rhizodep. & + & 0 & 32 & 119 & Swinnen (1994) \\
\hline 10 & Model rhizodep. & + & 0 & 160 & 119 & Changed: Swinnen (1994) \\
\hline 11 & Exudates elution & + & 118 & 0 & 0 & Kuzyakov and Siniakina (2001) \\
\hline
\end{tabular}


were added to the soil, (2) ${ }^{14} \mathrm{C}$ labeled model rhizodeposits were added to the soil with unlabeled plants.

Firstly, only ${ }^{12} \mathrm{C}$-D-glucose was used here instead of model rhizodeposits to enable comparability with the isotope dilution method of Cheng et al. (1993). This substitution is valid because low molecular weight sugars are the main component of root exudates (Jones and Darrah, 1993; Merbach et al., 1999). The other components of rhizodeposits—carboxylic acids, amino acids, etc.-have similar microbial availability as sugars (Kuzyakov and Demin, 1998). Originally (Swinnen, 1994), ${ }^{12} \mathrm{C}$ glucose solution was used as one variant.

Secondly, the same amount of unlabeled glucose (32 $\mu \mathrm{g} \mathrm{C} \mathrm{g}^{-1}$ ) was added to the soil with labeled plants (variant 5) as the amount of ${ }^{14} \mathrm{C}$ labeled glucose added to the soil with unlabeled plants. This permits comparison of these variants. Otherwise, as in the case of the original method, different results might merely reflect different treatment (no glucose addition into the soil with labeled plants). Moreover, one additional glucose concentration $\left(160 \mu \mathrm{g} \mathrm{C} \mathrm{g}^{-1}\right)$ was investigated. This level was used to check whether the results of the model rhizodeposition method depend on the glucose concentration. In the original paper, 1.23, 3.69 and $12.3 \mu \mathrm{g} \mathrm{C}$ glucose $\mathrm{g}^{-1}$ soil were investigated. However, these amounts were used in different experiments, making it difficult to compare the effect of glucose amount on the separation results.

${ }^{14} \mathrm{C}$ glucose $\left(119 \mathrm{kBq}\right.$ pot $\left.{ }^{-1}\right)$ solution was injected into the soil of variants 2, 3, 9 and 10 in the same way as in the isotope dilution method.

\subsection{3. ${ }^{14} \mathrm{CO}_{2}$ dynamics method}

The third method is based on the ${ }^{14} \mathrm{CO}_{2}$ efflux dynamics from soil after ${ }^{14} \mathrm{C}$ pulse labeling of shoots and subsequent modeling of the $\mathrm{C}$ flows in the rhizosphere (Kuzyakov et al., 1999, 2001). The $\mathrm{C}$ flow simulation reveals a time delay of $\mathrm{CO}_{2}$ coming from microbial utilization of rhizodeposits versus the $\mathrm{CO}_{2}$ coming from RR. Monitoring the ${ }^{14} \mathrm{CO}_{2}$ efflux from soil after ${ }^{14} \mathrm{C}$ pulse labeling of plants, fitting the model parameter on the measured ${ }^{14} \mathrm{CO}_{2}$ efflux, and subsequently modeling RR and microbial decomposition of exudates allow the independent estimation of both flows. This study used the second version of the model, in which all model parameters (except the two described above) were estimated in a separate experiment with ${ }^{14} \mathrm{C}$ labeling of L. perenne (Kuzyakov and Domanski, 2002). The ${ }^{14} \mathrm{CO}_{2}$ dynamics from the soil with labeled plants of the fourth variant (without glucose addition) were used to fit the two model parameters responsible for RR rate and exudation rate.

\subsubsection{Exudate elution method}

This method is based on the elution of exudates from the rhizosphere before soil microorganisms take them up and decompose them. The $\mathrm{CO}_{2}$ evolved from $\mathrm{RR}$ is collected simultaneously to the exudates elution. The soil was therefore flushed with a continuous flow of air-water mixture (Fig. 1). When this mixture left the soil, the water with eluted exudates was collected in a flask (3) containing $\mathrm{Ag}^{+}$solution (Micropur ${ }^{\circledR}$ ) to suppress microbial decomposition of leaked exudates before analysis (Deubel, 1996; Gransee and Wittenmayer, 2000). The $\mathrm{CO}_{2}$ evolved from $\mathrm{RR}$ was trapped in the $\mathrm{NaOH}$ solution (4) placed behind the flask for exudates.

The traps for ${ }^{14} \mathrm{CO}_{2}$ evolving from $\mathrm{RR}$ and those for eluted exudates were started at the beginning of labeling. The supply flask (1) was filled up regularly with $400 \mathrm{ml}$ of distilled water and the collecting flask (3) emptied. At the same time, $20 \mathrm{ml}$ of $0.25 \mathrm{M} \mathrm{NaOH}$ solution in the test tube (4) was exchanged. To obtain the dynamics of RR and exudation, the exchange of solutions was done five times on the first day after the labeling and only twice on the fourth day. Fresh air was introduced into each container once daily to compensate for the $\mathrm{O}_{2}$ consumed by soil microorganisms and roots. The method is described in detail by Kuzyakov and Siniakina (2001).

\subsection{Labeling}

The plants were labeled on day 64 and harvested on day 69. One day before labeling, the soil surface under the hole of the lid was sealed with a $2 \mathrm{~mm}$ layer of silicone rubber that overlaid a $2 \mathrm{~mm}$ layer of low melting point Paraffin. Three hours before the labeling the containers were flushed with $\mathrm{CO}_{2}$-free air to remove $\mathrm{CO}_{2}$ evolved prior to labeling.

Two kinds of labeling were used in different variants of the experiment (Table 1): pulse labeling of Lolium shoots in ${ }^{14} \mathrm{CO}_{2}$ atmosphere and injection of ${ }^{14} \mathrm{C}$ glucose as aqueous solution directly into the soil.

The ${ }^{14} \mathrm{C}$ pulse labeling has been described in detail (Kuzyakov et al., 1999, 2001; Domanski et al., 2001). Briefly, after sealing with silicone, each container with soil and roots was enclosed separately within a small chamber. Lolium shoots were carefully placed into the chamber. ${ }^{14} \mathrm{C}$ as $\mathrm{Na}_{2}^{14} \mathrm{CO}_{3}(118 \mathrm{kBq})$ was put into a $2 \mathrm{ml}$ Eppendorf micro test tube in the upper chamber and the chamber was then closed. One $\mathrm{ml}$ of $5 \mathrm{M}$ lactic acids was added to the $\mathrm{Na}_{2}^{14} \mathrm{CO}_{3}$ solution in the microtest tube through a Teflon pipe. This allowed complete evolution of ${ }^{14} \mathrm{CO}_{2}$ into the chamber atmosphere. Assimilation took place within $1 \mathrm{~h}$ after the pulsing of ${ }^{14} \mathrm{CO}_{2}$. After the $1 \mathrm{~h}$ labeling period, trapping of $\mathrm{CO}_{2}$ from the upper compartment was started to remove the remaining unassimilated ${ }^{14} \mathrm{CO}_{2}$. The air of the upper chamber was pumped through $20 \mathrm{ml}$ of $0.5 \mathrm{M} \mathrm{NaOH}$ solution to remove ${ }^{14} \mathrm{CO}_{2}$. Then the top of the chamber was removed. The plants of the variants $4-8$ and 11 were labeled in this manner in the ${ }^{14} \mathrm{CO}_{2}$ atmosphere.

The injection labeling variant involved adding aqueous ${ }^{14} \mathrm{C}$ glucose solution. The labeled $\mathrm{D}-\left[\mathrm{U}-{ }^{14} \mathrm{C}\right]$-glucose $(119 \mathrm{kBq})$ was added to $20 \mathrm{ml}$ aqueous solution of unlabeled D-glucose containing a total of 32 (variants 2 and 9) or 160 (variants 3 and 10) $\mathrm{mg}$ glucose and was 
mixed. This was then injected into different parts of the soil through three inlets in the lid of the polycarbonate filtration device (see Section 2.1) as $20 \mathrm{ml}$ aqueous solution using a syringe with a long needle. Soil of variants 2, 3, 9 and 10 were labeled with ${ }^{14} \mathrm{C}$ glucose in this manner. The unlabeled glucose was added in the same way to the soil of variants $5-8$. The injection and pulse labeling took place at the same time.

\subsection{Sample analysis}

During the experiment, the $\mathrm{CO}_{2}$ evolved from the soilroot compartment was trapped in $20 \mathrm{ml}$ of $0.5 \mathrm{M} \mathrm{NaOH}$ solution by continuous pumping $\left(100 \mathrm{~cm}^{3} \mathrm{~min}^{-1}\right)$ with a membrane pump (Fig. 1). Fig. 1 shows the detailed layout of the $\mathrm{CO}_{2}$ trapping and exudates collection system for the variants of the exudates elution method (variant 11). The chambers of all other variants were connected in the same way, yet without the flasks (1) and (3. Thus, the outlet of the soil-root chamber (2) was connected to the $\mathrm{NaOH}$ test tube (4) and inlet of membrane pump. The outlet of the membrane pump was connected to the three inlets of the lid of the soilroot chamber (2).

The trap for ${ }^{14} \mathrm{CO}_{2}$ evolved from the soil was changed every $2 \mathrm{~h}$ immediately after labeling, but after 2 days only twice daily. Five days after labeling, the soil-root chamber was opened, each plant cut at the base, and each root-soil column pulled out. Shoots and roots were dried at $60{ }^{\circ} \mathrm{C}$. Dry samples of shoots, roots, and soil were mixed and pulverized in a ball mill (Retsch Co.) prior to analyses for radioactivity and for total $\mathrm{C}$ and $\mathrm{N}$ determination.

${ }^{14} \mathrm{C}_{-} \mathrm{CO}_{2}$ collected in a $\mathrm{NaOH}$ solution was measured with the scintillation cocktail Rothiscint-22x (Roth Company) on $1 \mathrm{ml}$ aliquots of $\mathrm{NaOH}$ after the decay of chemiluminescence. The ${ }^{14} \mathrm{C}$ counting efficiency was about $89 \pm 1 \%$ and the ${ }^{14} \mathrm{C}$-activity measurement error did not exceed $2 \%$. The absolute ${ }^{14} \mathrm{C}$-activity was standardized by addition of $\mathrm{NaOH}$ solution as quencher to the scintillation cocktail and using a two-channel ratio method of extended standard (tSIE).

Radioactivity of shoots, roots and soil samples was measured after combustion of $1 \mathrm{~g}$ of sample within an oxidizer unit (Canberra Packard Co. Ltd, Model 307) with the scintillation cocktail Permafluor $\mathrm{E}^{+}$(Canberra Packard Co. Ltd) by a Liquid Scintillation Counter Tri-Carb 2000CA (Canberra Packard Co. Ltd).

The total $\mathrm{CO}_{2}$ content collected in $\mathrm{NaOH}$ solution was measured by titration with $0.2 \mathrm{M} \mathrm{HCl}$ against phenolphthalein after addition of $2.0 \mathrm{M} \mathrm{BaCl}_{2}$ solution (Black, 1965). Total $\mathrm{C}$ and $\mathrm{N}$ content in shoot and root was measured by a $\mathrm{C}-\mathrm{N}$-Analyzer (Carlo-Erba). The total $\mathrm{C}$ content in shoots was about $41 \pm 2 \%$ of dry mass and was accepted as a constant. Total $\mathrm{C}$ content in washed roots varied considerably because of different contents of mineral soil particles.

The experiment was conducted with four replicates for the variants listed in Table 1 . In a first step, the ${ }^{14} \mathrm{C}-\mathrm{CO}_{2}$ data were calculated as percentages of total assimilated ${ }^{14} \mathrm{C}$ for each replication. The total assimilated ${ }^{14} \mathrm{C}$ was calculated according to the equation

${ }^{14} \mathrm{C}_{\text {ass }}={ }^{14} \mathrm{C}_{\text {input }}-{ }^{14} \mathrm{C}_{n}-{ }^{14} \mathrm{C}_{r}$,

${ }^{14} \mathrm{C}_{\text {ass }}$ is activity of total assimilated ${ }^{14} \mathrm{C} ;{ }^{14} \mathrm{C}_{\text {input }}$ is total activity introduced as $\mathrm{Na}_{2}^{14} \mathrm{CO}_{2}(118 \mathrm{kBq}) ;{ }^{14} \mathrm{C}_{n}$ is activity of the $\mathrm{NaOH}$ solution after flushing the upper chamber; ${ }^{14} \mathrm{C}_{r}$ is the ${ }^{14} \mathrm{C}$ not volatilized after addition of lactic acid. In a second step the total ${ }^{14} \mathrm{C}-\mathrm{CO}_{2}$ (root-derived $\mathrm{CO}_{2}$ ) evolved from the soil was equated to $100 \%$ and the contributions of $\mathrm{RR}$ and rhizomicrobial contribution to the total root-derived $\mathrm{CO}_{2}$ were calculated. Standard deviation (SD) was calculated as a variability parameter.

\section{Results}

\subsection{Isotope dilution method}

In the variant without glucose addition, the dynamics of ${ }^{14} \mathrm{CO}_{2}$ efflux intensity were similar to the results observed in previous studies in our laboratory. Increasing glucose additions to the soil decreased specific ${ }^{14} \mathrm{C}$ activity of the evolved ${ }^{14} \mathrm{CO}_{2}$ (Fig. 2). Even 16 and $80 \mu \mathrm{g} \mathrm{g}{ }^{-1}$ soil reduced the activity of evolved ${ }^{14} \mathrm{CO}_{2}$ by about $20 \%$. Further addition of unlabeled glucose diminished the evolved ${ }^{14} \mathrm{CO}_{2}$ activity by up to $39 \%$ of the variant without glucose addition. To calculate the function of evolved ${ }^{14} \mathrm{CO}_{2}$ from the amount of added glucose $\left({ }^{14} \mathrm{CO}_{2} \%\right.$ (Glucose)), the parameter $(k)$ of exponential equation with a constant $\mathrm{RR}$ were fitted on the measured data:

${ }^{14} \mathrm{CO}_{2} \%($ Glucose $)=(100-\mathrm{RR}) \exp (-k$ Glucose $)+\mathrm{RR}$

where RR is root respiration, Glucose is the concentration of added unlabeled glucose, $k$ is a proportionality coefficient of decreasing specific activity.

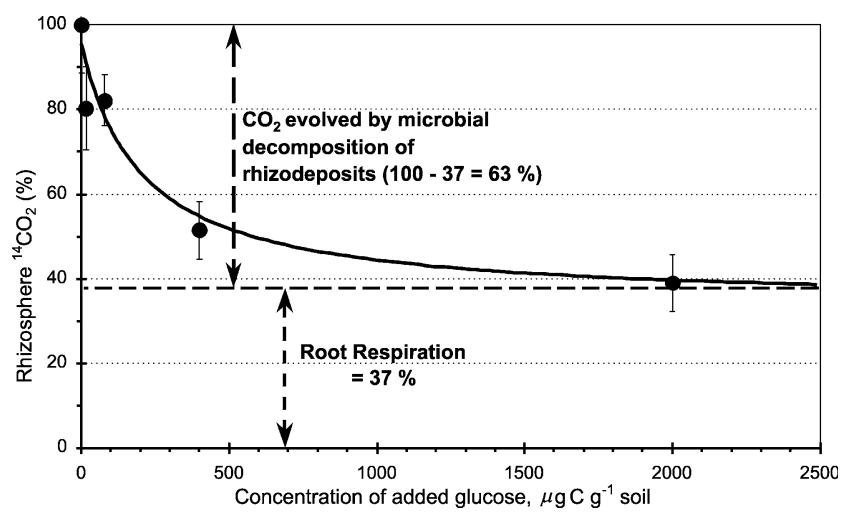

Fig. 2. Separation of RR and rhizomicrobial respiration using the isotope dilution method (Cheng et al., 1993): Dilution of ${ }^{14} \mathrm{CO}_{2}$ efflux from soil with ${ }^{12} \mathrm{CO}_{2}$ coming from different amounts of added unlabelled glucose. Vertical bars show standard deviation. 
The fitted RR coefficient shows that RR amounts to about $37 \%$ of total rhizosphere respiration (Fig. 2). The difference to $100 \%$ yields the respiration of microorganisms decomposing rhizodeposits in the soil of the variant without glucose addition. These results are very close to those presented in Cheng et al. (1993) original contribution: $41 \%$ for $\mathrm{RR}$ and $59 \%$ for rhizomicrobial respiration. The slightly lower RR here probably reflects the much higher glucose amount $\left(4000 \mu \mathrm{g} \mathrm{C} \mathrm{g}^{-1}\right)$ added in the soil of variant 8 .

\subsection{Model rhizodeposition method}

The calculation of RR and rhizomicrobial respiration by the model rhizodeposition method assumes a constant ratio between microbially respired ${ }^{14} \mathrm{C}\left({ }^{14} \mathrm{C}-\mathrm{MR}\right)$ and ${ }^{14} \mathrm{C}$ remaining in the soil $\left({ }^{14} \mathrm{C}\right.$-Soil $)$ in the variant with natural rhizodeposits and with model rhizodeposits (Swinnen, 1994)

${ }^{14} \mathrm{C}-\mathrm{MR}_{\mathrm{C}} /{ }^{14} \mathrm{C}-$ Soil $_{\mathrm{C}}={ }^{14} \mathrm{C}-\mathrm{MR}_{\mathrm{Glu}} /{ }^{14} \mathrm{C}$-Soil $\mathrm{Glu}$

where ${ }^{14} \mathrm{C}-\mathrm{MR}_{\mathrm{C}}$ and ${ }^{14} \mathrm{C}-\mathrm{MR}_{\mathrm{Glu}}$ are ${ }^{14} \mathrm{C}$ activity evolved by microbial respiration from the soil of the control variant with labeled plants and from the soil with added ${ }^{14} \mathrm{C}$ glucose, and ${ }^{14} \mathrm{C}$-Soil $\mathrm{C}$ and ${ }^{14} \mathrm{C}$-Soil $\mathrm{Glu}_{\mathrm{Glu}}$ are ${ }^{14} \mathrm{C}$ activity remaining in soil residue in the variant with labeled plants and in the variant with added ${ }^{14} \mathrm{C}$ glucose.

The two glucose levels tested here $\left(16\right.$ and $80 \mu \mathrm{g} \mathrm{g}^{-1}$ soil) differ from those of Swinnen (1994) (1.23 and $3.67 \mu \mathrm{g} \mathrm{g}^{-1}$ soil). The latter concentrations were close together and investigated in different experiments, making it difficult to estimate the effect of the amount of added glucose. The significantly different concentrations chosen here show that RR depends on the glucose concentration (Table 1): at the lower value, RR was $83 \pm 1 \%$ of total rootderived $\mathrm{CO}_{2}$, whereas at the higher value it was $71 \pm 6 \%$. Thus, adding an additional $64 \mu \mathrm{g}$ glucose $\mathrm{g}^{-1}$ soil decreased the contribution of microbial respiration by $12 \%$. According to this method, the microbial respiration of the exudates is only about $17-29 \%$ of total root-derived $\mathrm{CO}_{2}$. However, these results are 2-3 times higher than in Swinnen (1994), who reported values of only $5-11 \%$. I explain this result by the higher glucose concentration used in my experiment.

\section{3. ${ }^{14} \mathrm{CO}_{2}$ dynamics method}

The separation of root and microbial respiration by this method is based on the assumption that these two processes are predominant in total root-derived ${ }^{14} \mathrm{CO}_{2}$ efflux at different times following ${ }^{14} \mathrm{C}$ pulse labeling of shoots. The most rapid process is the $\mathrm{CO}_{2}$ efflux from $\mathrm{RR}$, which predominates in the first day after labeling (Fig. 3, phase 1). The $\mathrm{CO}_{2}$ evolution by microbial respiration of root exudates occurs later than RR because it consists of a chain of

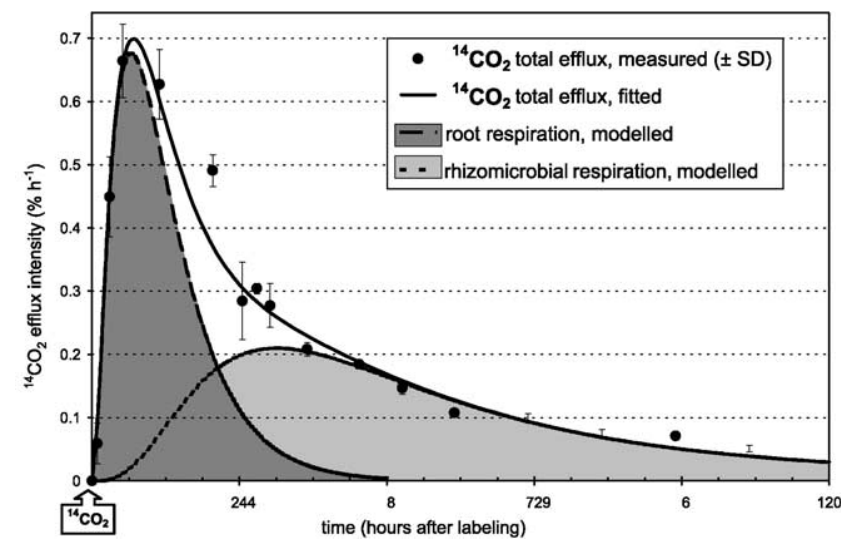

Fig. 3. Separation of RR and rhizomicrobial respiration using the ${ }^{14} \mathrm{CO}_{2}$ efflux dynamics method (Kuzyakov et al., 1999, 2001; Kuzyakov and Domanski, 2002): ${ }^{14} \mathrm{CO}_{2}$ efflux evolved by RR appears earlier than ${ }^{14} \mathrm{CO}_{2}$ respired by rhizomicrobial respiration. Vertical bars show standard deviation.

successive processes: exudation of organic substances from the root, their intake by microorganisms and their use for microbial respiration. It predominates between the second and fifth day after labeling (Fig. 3, phase 2). The microbial respiration of dead roots is very slow (on the time scale used) and therefore contributes only negligibly to the total ${ }^{14} \mathrm{CO}_{2}$ efflux in these first days. It predominates after day 5 (Kuzyakov et al., 2001; Domanski et al., 2001).

Using the model of below-ground $\mathrm{C}$ translocation described earlier (Kuzyakov and Domanski, 2002) allows separate simulation of root and rhizomicrobial respiration (Fig. 3). The fitted curve of the total root-derived $\mathrm{CO}_{2}$ and the subdivision in (1) RR and (2) microbial respiration of root exudates and dead roots substantiate these assumptions. In order to calculate the total amount of $C$ passed through $\mathrm{RR}$ and root exudation separately each process was integrated. The former contributed $45 \%$, the latter about $55 \%$ of total root-derived $\mathrm{CO}_{2}$ (measured as ${ }^{14} \mathrm{CO}_{2}$ ). These relationships are close to previously reported ones (Kuzyakov et al., 1999, 2001). Note here that prolonging $\mathrm{CO}_{2}$ monitoring period for longer than 5 days will increase the contribution of rhizomicrobial respiration and diminish the contribution of RR.

\subsection{Exudates elution method}

This method of separating the two respiration processes is based on the blowout of ${ }^{14} \mathrm{CO}_{2}$ coming from RR by continuous air pumping and simultaneous leakage of original root exudates as well as of organic compounds modified by microorganisms by continuous water flow through the rhizosphere soil.

${ }^{14} \mathrm{C}$ activity was found in the ${ }^{14} \mathrm{CO}_{2}$ coming from the rhizosphere and in the water with eluted organic compounds. Note that the eluted ${ }^{14} \mathrm{C}$-labeled compounds stem from original root exudates as well as from the organic 
compounds metabolized and modified by microorganisms during elution.

The total ${ }^{14} \mathrm{C}$ activity found in ${ }^{14} \mathrm{CO}_{2}$ coming from the soil corresponded to $8.5 \%$ of total assimilated ${ }^{14} \mathrm{C}$, and the corresponding value in eluted organics was $2.3 \%$. Thus, rhizomicrobial respiration contributed at least $19 \%$ to the total root-derived $\mathrm{CO}_{2}$. This yields a ratio $\left({ }^{14} \mathrm{CO}_{2}\right.$ respired $/{ }^{14} \mathrm{C}$ eluted) of about 4.5 over the whole observation period. However, this ratio strongly depends on sampling time, especially during the first 2 days after start of assimilation (labeling). The first samples, taken $1 \mathrm{~h} 40 \mathrm{~min}$ after the start of labeling, revealed nine times more ${ }^{14} \mathrm{C}$ in ${ }^{14} \mathrm{CO}_{2}$ compared to ${ }^{14} \mathrm{C}$ in eluted root-derived organic compounds. The maximum ${ }^{14} \mathrm{CO}_{2}$ efflux occurred roughly $12 \mathrm{~h}$ after labeling, but there were two ${ }^{14} \mathrm{C}$ maxima in eluted root-derived organic compounds: the first after $5 \mathrm{~h}$ and the second between 20 and $24 \mathrm{~h}$. Note that both these maxima correspond with the light phases (Fig. 4), i.e. they occurred during the photosynthesis period. On day 3 (ca. $40 \mathrm{~h}$ ) after labeling, a smaller third peak appeared also during the light phase. In contrast, both minima measured during the first 2 days occurred at night.

The ratio of ${ }^{14} \mathrm{CO}_{2}$ to ${ }^{14} \mathrm{C}$ in eluted root-derived organic compounds was about 6-9 at night and dropped to about 2-3 during the assimilation time (Fig. 5). Exudation intensity is thus much higher during the daytime. Two days after assimilation the ratio showed no diurnal dynamics and remained on the level of 5-6.

Exudation intensity decreased after the second maximum and, two days after labeling, was below $0.01 \%{ }^{14} \mathrm{C} \mathrm{h}^{-1}$. This suggests that 2 days after assimilation, most of the ${ }^{14} \mathrm{C}$ activity was located in the non-soluble organic compounds, such as root hairs, sloughed cells and partially in mucigels, microbial biomass, etc. Therefore, the ${ }^{14} \mathrm{CO}_{2}$ coming from the rhizosphere on day 3 mainly originates from microbial decomposition of root hairs, sloughed cells and turnover of

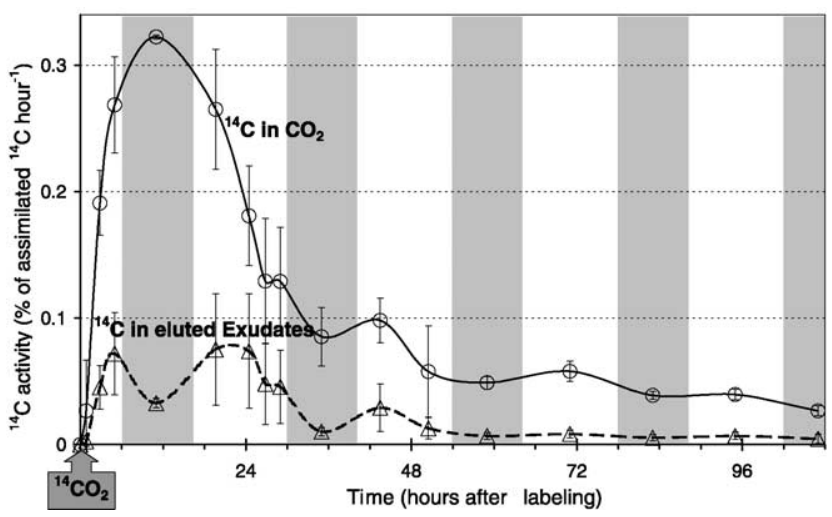

Fig. 4. Dynamics of ${ }^{14} \mathrm{C}$ in RR and exudates separated with the exudates elution method after ${ }^{14} \mathrm{C}$ pulse labeling of shoots: Elution of root exudates occurs simultaneously to blow out of ${ }^{14} \mathrm{CO}_{2}$ coming from RR. Vertical bars show standard deviation. Grey area shows the nighttime (Kuzyakov and Siniakina, 2001).

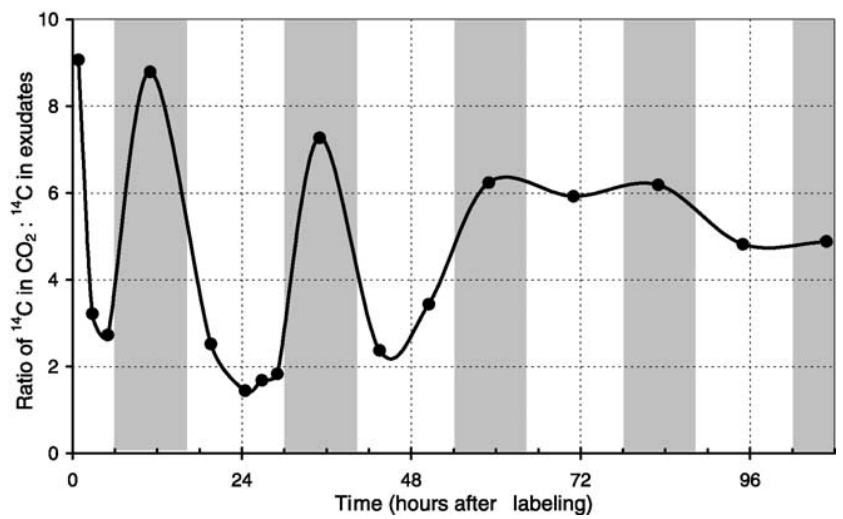

Fig. 5. Quotient between ${ }^{14} \mathrm{C}$ in RR and in exudates during four and a half days after assimilation. Grey area shows the nighttime. (Kuzyakov and Siniakina, 2001).

microorganisms. Strictly speaking, it is no longer connected with the mineralization of actual root exudates (water soluble low molecular organic substances).

\section{Discussion}

Four different methods allowing separate estimation of $\mathrm{RR}$ and rhizomicrobial respiration in non-sterile soil were tested in this experiment under the same environmental and experimental conditions. Thus, the observed differences between investigated methods can be only attributed to the methods themselves and to their assumptions. This makes it important to enumerate the assumptions considered by each method, to expose possible shortcomings, and to evaluate their possible effects on the separation results.

\subsection{Isotope dilution method}

Some assumptions of this method were discussed by Cheng et al. (1993, 1994, 1996): (1) injection of glucose does not produce short-term effects on plant physiology other than diluting the root exudates; (2) glucose is compatible with root exudates in terms of substrate specificity; (3) adding glucose does not stimulate or suppress the microbial activities in the rhizosphere during the experiment; (4) the dilution of ${ }^{14} \mathrm{CO}_{2}$ evolved from the soil shows a simple and proportional relationship with the amounts of added glucose. The last assumption enables calculating the ratio of RR to rhizomicrobial respiration. In my opinion, all these assumptions are acceptable because they have no effect on the separation results. However, one very important hidden assumption not discussed in the original paper has also to be considered: the ratio of root to rhizomicrobial respiration is accepted as fixed during the experiment and is extrapolated for the whole period of rhizosphere respiration. Based on the ${ }^{14} \mathrm{CO}_{2}$ efflux, Warembourg and Billes (1979), Nguyen et al. (1999) and Kuzyakov et al. $(1999,2001)$ have indirectly demonstrated that this ratio changes during plant development after a ${ }^{14} \mathrm{C}$ 
pulse. An additional shortcoming of this method is that the above ratio can be registered only briefly (about $4-5 \mathrm{~h}$ ) after supplying the soil with glucose. After this lag-period the microorganisms begin to grow and the third and fourth assumptions can no longer be accepted.

\subsection{Model rhizodeposition method}

This method assumes that the ${ }^{14} \mathrm{CO}_{2}$ efflux from soil with added labeled model rhizodeposits corresponds to rhizomicrobial respiration in the soil with applied above-ground labeling of plants (Swinnen, 1994). The ${ }^{14} \mathrm{CO}_{2}$ efflux from the soil with added model rhizodeposits is monitored and compared with the ${ }^{14} \mathrm{CO}_{2}$ efflux from the soil with pulse labeled plants (Swinnen, 1994). The ratio of respired and remaining ${ }^{14} \mathrm{C}$ in both variants is used to estimate the $\mathrm{RR}$ (Eq. (2)). Accordingly, the contribution of RR of 30-day-old wheat and barley to total root-derived $\mathrm{CO}_{2}$ was between 89 and $95 \%$. These results appear too high considering the high concentration of exudates in the rhizosphere (Cheng et al., 1993) and oppose many other investigations about partitioning of the ${ }^{14} \mathrm{CO}_{2}$ efflux (Helal and Sauerbeck, 1989; Kuzyakov et al., 1999; reviewed by Kuzyakov and Domanski, 2000). The possible source of the artifacts may be the missing addition of unlabeled model rhizodeposits to the soil with labeled plants. This possible shortcoming was improved in the reported experiment.

The hidden assumption of the method is that the microbial utilization of glucose and its absorption by clay minerals and soil organic matter is the same in the rhizosphere and in the bulk soil. When glucose (in this experiment) or model rhizodeposits (in the original paper) are artificially injected into the soil, only part of the added amount is located in the rhizosphere. The main part is distributed in the root-free soil. The microbial decomposition of glucose and other rhizodeposits to $\mathrm{CO}_{2}$ in the rhizosphere is higher than in the bulk soil because rhizosphere microorganisms are more strongly limited by $\mathrm{N}$ and other nutrients. Moreover, different microbial communities of rhizosphere and root-free soil may be responsible for various yield factors $(\mathrm{Y})$ (Payne, 1970) and conversion to $\mathrm{CO}_{2}$. Finally, many rhizosphere microorganisms are located directly on the rhizoplane at the exudation sites. The exuded organic substances can be directly taken up by microorganisms and have no chance to be absorbed by clay minerals and soil organic matter. After the experiment, more ${ }^{14} \mathrm{C}$ therefore remains in the bulk soil with added ${ }^{14} \mathrm{C}$ glucose compared with the ${ }^{14} \mathrm{C}$ remaining in the rhizosphere. This result decreases the contribution of rhizomicrobial respiration according to Eq. (2) and increases the contribution of $\mathrm{RR}$ to the total root-derived $\mathrm{CO}_{2}$.

\section{3. ${ }^{14} \mathrm{CO}_{2}$ dynamics method}

This method is based on the dynamics of ${ }^{14} \mathrm{CO}_{2}$ efflux from soil after pulse labeling (Kuzyakov et al., 1999; 2001).
It assumes that ${ }^{14} \mathrm{CO}_{2}$ generated by $\mathrm{RR}$ appears earlier than that derived from rhizomicrobial respiration. This delay reflects the time necessary for the synthesis of exudates, for the exudation and secretion processes, and for the uptake and utilization of rhizodeposits by microorganisms (Warembourg and Billes, 1979). However, this time delay is not introduced in the model artificially (no time lags in the model) and the parameters responsible for RR and root exudation are of the same order. Therefore, this delay occurs because of the successive processes.

The following other assumptions are used in the $\mathrm{C}$ flow model by the dynamics separation method (Kuzyakov and Domanski, 2002): (1) The plant biomass does not significantly change during the whole period of ${ }^{14} \mathrm{CO}_{2}$ monitoring until the end of $\mathrm{C}$ allocation. (2) The influence of plant growth (reverse transport of ${ }^{14} \mathrm{C}$-labeled compounds from the roots to the shoots) on partitioning processes was omitted from the model. (3) The model does not consider the diurnal changes in assimilation, translocation and respiration activity. (4) All ${ }^{14} \mathrm{C}$ flows in the model are described by first-order kinetics. All these assumptions are used in developing the model and have no short-time effects (several days after ${ }^{14} \mathrm{C}$ pulse labeling) on the separation results.

\subsection{Exudates elution method}

The last method is based on the elution of exudates from soil before microorganisms can utilize them. It also includes many assumptions and shortcomings (Kuzyakov and Siniakina, 2001). The first shortcoming involves the limited elution of some mucigels secreted by roots as well as the ${ }^{14} \mathrm{C}$ incorporated in root hairs and sloughed root cells. Merbach et al. (1999), however, showed that up to between 60 and $80 \%$ of the root-borne organic compounds was mainly water-soluble. Similarly, Jones and Darrah (1993) found that, depending on the removal of nutrient solution, soluble low molecular weight exudates account for between 48 and $86 \%$ of root-derived organic compounds.

The exudates in this method are mainly eluted by preferential flow. Therefore, during exudation, the processes near the preferential flow pathway might differ from those farther away. The mean time for exudate elution by preferential flow amounts to about 5-10 min. The elution time of organic substances exuded far from the main water streams is longer, but it is difficult to estimate it. Thus, microorganisms can decompose the exudates during their transport from the root to the exudate collector. The eluted organics therefore consist not only of the original exudates but also include substances modified by microorganisms during elution. This shortcoming may depend on the soil texture. Sandy soils are probably more suitable for the separation with this method than the clay soils.

Continuous water flow in the microcosm may change the amount and composition of the $\mathrm{C}$ released by the roots. Jones and Darrah (1993) reported an up to $98 \%$ re-uptake of 
maize exudates in a sterile static nutrient solution culture. Using ${ }^{14} \mathrm{C}$ labeled glucose, Paterson and Sim (1999) show a $75 \%$ re-uptake of exudates by L. perenne roots in a sterile nutrient solution culture. However, it is doubtful whether such re-uptake plays a significant role under non-sterilized soil conditions. Under field conditions, microorganisms on the root surface strongly compete with roots for exudates. In our system the removal of exudates from roots by water flow may be accepted as uptake by microorganisms.

These shortcomings of the exudates elution method may increase the ${ }^{14} \mathrm{C}$ in $\mathrm{CO}_{2}$, thereby decreasing it in exudates. Therefore, the ${ }^{14} \mathrm{C}$ measured in eluted organic compounds is probably underestimated and the ${ }^{14} \mathrm{C}$ in $\mathrm{CO}_{2}$ overestimated. Hence it can be concluded that the method shows only the minimal amount of water-soluble exudates released from roots.

Despite its shortcomings, one key advantage over the other tested methods deserves mention: the exudates elution method is only one technique allowing physical separation of different $\mathrm{CO}_{2}$ sources. The three other methods are based on calculations and not on physical separation. Therefore their results cannot be verified directly and remain unverifiable hypotheses. The physical separation in the exudates elution method shows that the ratio of $\mathrm{CO}_{2}$ derived from $\mathrm{RR}$ and $\mathrm{C}$ respired by microbial utilization of rhizodeposits depends on the diurnal dynamics of photosynthesis (Figs. 4 and 5): At the light-on events the exudation intensity is $2-3$ times higher than at night, while RR remains nearly constant, independent of photosynthesis. Thus, the clear diurnal dynamics of total and rootderived $\mathrm{CO}_{2}$ efflux by growing wheat on a $\mathrm{C}_{4}$ soil observed by Kuzyakov and Cheng (2001) could be explained by diurnal dynamics of exudation and not by RR.

The advantage of physical separation of root exudates by this method could be used later to study the composition of organic substances exuded by roots in non-sterile soils. Until now such investigations have been conducted only for nutrient solution studies or sterilized soils, in which the root growth conditions are unnatural (Bowen, 1980; Schönwitz and Ziegler, 1988; Merbach et al., 1990; Meharg and Killham, 1991; Schulze et al., 1994).

\subsection{General comparison of the four methods and conclusions}

In spite of the different approaches and assumptions used by each method, there is some important conformity: All four methods are based on the pulse labeling of shoots in ${ }^{14} \mathrm{CO}_{2}$ atmosphere and subsequent monitoring of ${ }^{14} \mathrm{CO}_{2}$ efflux from the soil. Labeling is a mandatory requirement to separate root-derived $\mathrm{CO}_{2}$ from SOM-derived $\mathrm{CO}_{2}$. Continuous labeling is hardly useful for such separations, especially for isotope dilution and ${ }^{14} \mathrm{CO}_{2}$ dynamics methods. Theoretically ${ }^{13} \mathrm{C}$ could be used instead of ${ }^{14} \mathrm{C}$. However, the very high sensitivity of ${ }^{14} \mathrm{C}$ isotope

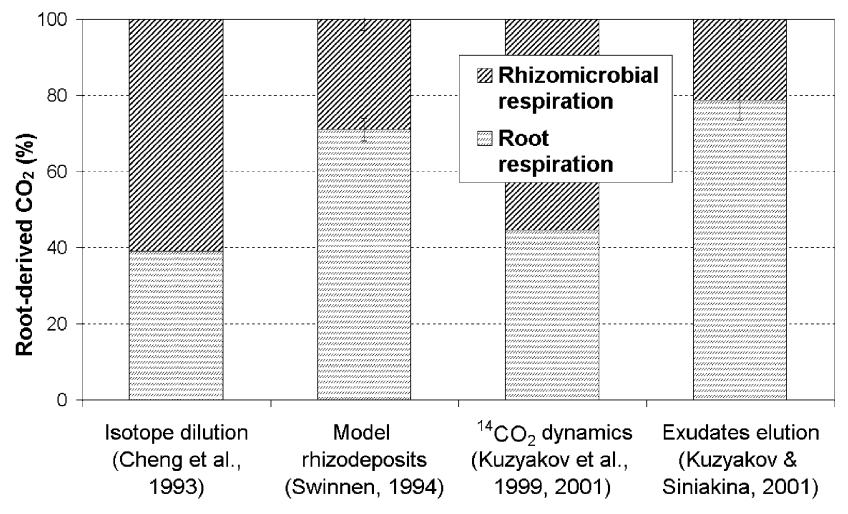

Fig. 6. General comparison of the results obtained by four methods separating RR and rhizomicrobial respiration in non-sterile soils. Mean values $\pm \mathrm{SD}$ are shown. $\mathrm{SD}$ for isotope dilution and ${ }^{14} \mathrm{CO}_{2}$ dynamics methods cannot be calculated.

analyses, its easy application and cheap analyses make ${ }^{14} \mathrm{C}$ an unmatched tracer for such studies.

Fig. 6 shows the generalized results observed by each method tested. Two pairs of results were similar: The isotope dilution and the dynamics method show similar amounts of RR, 39 and $45 \%$ of total root-derived $\mathrm{CO}_{2}$ efflux, respectively. The RR estimated using the model rhizodeposition technique and the exudates elution method was 71 and $79 \%$ of total root-derived $\mathrm{CO}_{2}$ efflux, respectively.

Interestingly, similar results were obtained by the isotope dilution and the ${ }^{14} \mathrm{CO}_{2}$ dynamics method despite alternative underlying assumptions. This mutually exclusive assumption involves the ratio of ${ }^{14} \mathrm{C}$ in $\mathrm{CO}_{2}$ coming from RR to that derived by microbial respiration of rhizodeposits after the pulse labeling. The former method assumes that this ratio is constant during the observation, whereas the latter method accepts this ratio as variable. The results of the exudates elution method, however, show that this ratio is not constant, that it changes after labeling, and that it depends on photosynthesis cycles (Fig. 4).

As described earlier, the exudates elution method shows only the minimal amount of water-soluble exudates released from roots. Nonetheless, this minimal amount is about two to three times higher than that estimated by the original model rhizodeposition method (Swinnen, 1994) and is similar to the results of the improved model rhizodeposition method used in our experiment. The model rhizodeposition method therefore also underestimates rhizomicrobial respiration and strongly overestimates RR. Thus, the addition of ${ }^{14} \mathrm{C}$-labeled model rhizodeposits to soil (Swinnen, 1994) is unacceptable as a satisfactory method for separating RR from microbial respiration of exudates.

The amount of eluted root-derived organic substances measured with the exudates elution method is about two times smaller than that measured with the isotope dilution (Cheng et al., 1993) or ${ }^{14} \mathrm{CO}_{2}$ dynamics method (Kuzyakov et al., 1999, 2001). A similar factor of about two emerged 
when comparing the dipping method (almost 100\% of cold-water-soluble exudates) with the percolation method (comparable with the presented Siphon method) in extracting exudates from the rhizosphere (Gransee and Wittenmayer, 2000). Thus, we can accept that roughly half of the substances exuded by roots are waterinsoluble and that microorganisms will mineralize a part (no more than half) of the exuded organic compounds during the leaching process through the loamy soil. Merbach et al. (1999) also found that the amount of water-insoluble secretions comprises less than $40 \%$ of root-borne organic compounds. We can therefore conclude that RR contributes about $40-50 \%$ to the rootderived $\mathrm{CO}_{2}$ efflux. The remaining $50-60 \%$ comprise the microbial decomposition of root exudates and other rhizodeposits. We can also conclude that the longer the monitoring period of $\mathrm{CO}_{2}$ efflux after pulse labeling, the higher the contribution of rhizomicrobial respiration to the total root-derived $\mathrm{CO}_{2}$ efflux from soil.

\section{Acknowledgments}

This research was supported by the German Research Foundation (DFG). I am greatly thankful to S. Siniakina for radiochemical analysis, D. Eckstein (Department of Physics) for permitting the use of his equipment, and G. Domanski for review of an earlier version of this manuscript.

\section{References}

Barber, D.A., Martin, J.K., 1976. The release of organic substances by cereal roots into soil. New Phytologist 76, 69-80.

Black, C.A. (Ed.), 1965. Methods of Soil Analysis, Part 2. American Society of Agronomy Inc. Publisher, Madison, Wisconsin, pp. 15621565.

Blagodatsky, S.A., Larionova, A.A., Evdokimov, I.V., 1993. Contribution of root respiration to $\mathrm{CO}_{2}$ emission from soil. In: Zavarzin, G.A., Kudeyarov, V.N. (Eds.), Soil Respiration, IPP, Pushchino, pp. $26-32$.

Bowen, G.D., 1980. Misconceptions, concepts and approaches in rhizosphere biology. In: Ellwood, D.C., Hedger, J.N., Latham, M.J., Lynch, J.M., Stater, J.H. (Eds.), Contemporary Microbial Ecology, Academic Press, London, pp. 283-304.

Cheng, W., Kuzyakov, Y., 2002. Root effects on decomposition of organic matter. In: Wright, S., (Ed.), Roots and Soil Management: Interactions between Roots and Soil, Soil Science Society of America Book Series, Soil Science Society of America, Madison, WI, in press.

Cheng, W., Coleman, D.C., Carroll, C.R., Hoffman, C.A., 1993. In situ measurement of root respiration and soluble $\mathrm{C}$ concentrations in the rhizosphere. Soil Biology \& Biochemistry 25, 1189-1196.

Cheng, W., Coleman, D.C., Carroll, C.R., Hoffman, C.A., 1994. Investigating short-term carbon flows in the rhizospheres of different plant species, using isotopic trapping. Agronomy Journal 86, $782-788$.

Cheng, W., Zhang, Q., Coleman, D.C., Carroll, C.R., Hoffman, C.A., 1996. Is available carbon limiting microbial respiration in the rhizosphere? Soil Biology \& Biochemistry 28, 1283-1288.
Deubel, A., 1996. Einfluß wurzelbürtiger organischer Kohlenstoffverbindungen auf Wachstum und Phosphatmobilisierungsleistung verschiedener Rhizosphärenbakterien. Aachen, Shaker.

Domanski, G., Kuzyakov, Y., Siniakina, S.V., Stahr, K., 2001. Carbon flows in the rhizosphere of Lolium perenne. Journal of Plant Nutrition and Soil Science 164, 381-387.

Edwards, N.T., Harris, W.F., 1977. Carbon cycling in a mixed deciduous forest floor. Ecology 58, 431-437.

Gransee, A., Wittenmayer, L., 2000. Qualitative and quantitative analysis of water-soluble root exudates in relation to plant species and development. Journal of Plant Nutrition and Soil Science 163, $381-385$.

Groleau-Renaud, V., Plantureux, S., Guckert, A., 1998. Influence of plant morphology on root exudation of maize subjected to mechanical impedance in hydroponic conditions. Plant and Soil 201, 231-239.

Hanson, P.J., Edwards, N.T., Garten, C.T., Andrews, J.A., 2000. Separating root and soil microbial contributions to soil respiration: a review of methods and observations. Biogeochemistry 48, $115-146$.

Helal, H.M., Sauerbeck, D., 1989. Carbon turnover in the rhizosphere. Zeitschrift für Pflanzenernährung und Bodenkunde 152, 211-216.

Helal, H.M., Sauerbeck, D., 1991. Short term determination of the actual respiration rate of intact plant roots. In: McMichal, B.L., Person, H. (Eds.), Plant Roots and Their Environment, Elsevier, Amsterdam, pp. $88-92$.

Hodge, A., Grayston, S.J., Ord, B.G., 1996. A novel method for characterisation and quantification of plant root exudates. Plant and Soil 184, 97-104.

Jones, D.L., Darrah, P.R., 1993. Re-sorption of organic compounds by roots of Zea mays L. and its consequences in the rhizosphere. II. Experimental and model evidence for simultaneous exudation and re-sorption of soluble C compounds. Plant and Soil 153, $47-59$.

Killham, K., Yeomans, C., 2001. Rhizosphere carbon flow measurement and implications: from isotopes to reporter genes. Plant and Soil 232, 91-96.

Kuzyakov, Y.V., 2001. Tracer studies of carbon translocation by plants from the atmosphere into the soil (a review). Eurasian Soil Science 34, $28-42$.

Kuzyakov, Y.V., 2002. Review. factors affecting rhizosphere priming effects. Journal of Plant Nutrition and Soil Science 165 (4), 382-396.

Kuzyakov, Y., Cheng, W., 2001. Photosynthesis controls of rhizosphere respiration and organic matter decomposition. Soil Biology \& Biochemistry 33, 1915-1925.

Kuzyakov, Y., Demin, V., 1998. $\mathrm{CO}_{2}$ efflux by rapid decomposition of low molecular organic substances in soils. Sciences of Soils 3. http://link.springer.de/link/service/journals/10112 /fpapers/8003001/ 80030002.htm.

Kuzyakov, Y., Domanski, G., 2000. Carbon input by plants into the soil. Review. Journal of Plant Nutrition and Soil Science 163, 421-431.

Kuzyakov, Y., Domanski, G., 2002. Model for rhizodeposition and $\mathrm{CO}_{2}$ efflux from planted soil and its validation by ${ }^{14} \mathrm{C}$ pulse labelling of ryegrass. Plant and Soil 239, 87-102.

Kuzyakov, Y., Siniakina, S.V., 2001. Siphon method of separating rootderived organic compounds from root respiration in non-sterile soil. Journal of Plant Nutrition and Soil Science 164, 511-517.

Kuzyakov, Y., Kretzschmar, A., Stahr, K., 1999. Contribution of Lolium perenne rhizodeposition to carbon turnover of pasture soil. Plant and Soil 213, 127-136.

Kuzyakov, Y., Ehrensberger, H., Stahr, K., 2001. Carbon partitioning and below-ground translocation by Lolium perenne. Soil Biology \& Biochemistry 33, 61-74.

Martin, J.K., 1977. The chemical nature of the carbon-14-labelled organic matter released into soil from growing wheat roots, Soil 
Organic Matter Studies, vol. 1. International Atomic Energy Agency, Vienna, pp. 197-203.

Meharg, A.A., Killham, K., 1991. Anew method of quantifying rootexudation in the presence of soil microflora. Plant and Soil 133, 111-116.

Merbach, W., Ruppel, S., 1992. Influence of microbial colonization on ${ }^{14} \mathrm{CO}_{2}$ assimilation and amounts of root-borne ${ }^{14} \mathrm{C}$ compounds in soil. Photosynthetica 26, 551-554.

Merbach, W., Knof, G., Miksch, G., 1990. Quantifizierung der CVerwertung im System Pflanze-Rhizosphäre-Boden. In: KohlenstoffStickstoffdynamik im Boden sowie Programme zur Steuerung der organischen Düngung. Akademie der Landwirtschafts-wissenschaften, Berlin, Tagungsbericht, 295, pp. 57-63.

Merbach, W., Mirus, E., Knof, G., Remus, R., Ruppel, S., Russow, R., Gransee, A., Schulze, J., 1999. Release of carbon and nitrogen compounds by plant roots and their possible ecological importance. Journal of Plant Nutrition and Soil Science 162, 373-383.

Merck ${ }^{\circledR}$-Laborkatalog, 2000. Verbrauchsmaterialien und Geräte, Merck Eurolab GmbH, Darmstadt, p. 516.18.

Nguyen, C., Todorovic, C., Robin, C., Christophe, A., Guckert, A., 1999. Continuous monitoring of rhizosphere respiration after labelling of plant shoots with ${ }^{14} \mathrm{CO}_{2}$. Plant and Soil 212, 191-201.
Paterson, E., Sim, A., 1999. Rhizodeposition and C-partitioning of Lolium perenne in axenic culture affected by nitrogen supply and defoliation. Plant and Soil 216, 155-164.

Payne, W.J., 1970. Energy yields and growth of heterotrophs. Annual Review of Microbiology 24, 17-52.

Schönwitz, R., Ziegler, H., 1988. Interaction of maize roots and rhizosphere microorganisms. Zeitschrift für Pflanzenernährung und Bodenkunde $152,217-222$.

Schulze, J., Gransee, A., Wittenmayer, L., Pöschel, G., Schilling, G., 1994. Der Einflu $\beta$ von Wachstumsubstrat und Mikrobenbesatz der Wurzel auf die Ausscheidung und Umsetzung organischer Verbindungen in der Rhizosphäre von Maispflanzen. In: Merbach, W., (Ed.), Mikroökologische Prozesse im System Pflanze-Boden, 5, Borkheider Seminar zur Ökophysiologie des Wurzelraumes, Teubner, Stuttgart, pp. 144-150.

Swinnen, J., 1994. Evaluation of the use of a model rhizodeposition technique to separate root and microbial respiration in soil. Plant and Soil 165, 89-101.

Warembourg, F.R., Billes, G., 1979. Estimating carbon transfers in the plant rhizosphere. In: Harley, J.L., Scott Russell, R. (Eds.), The Soil-Root Interface, Academic Press, London, pp. 183-196. 